\title{
Dietary inclusion of salmon, herring and pompano as oily fish reduces CVD risk markers in dyslipidaemic middle-aged and elderly Chinese women
}

\author{
Jian Zhang ${ }^{1,2,3}$, Chunrong Wang ${ }^{1}$, Lixiang $\mathrm{Li}^{1}$, Qingqing Man ${ }^{1}$, Liping Meng ${ }^{1}$, Pengkun Song ${ }^{1}$, \\ Livar Frøyland ${ }^{2}$ and Zhen-Yu Du ${ }^{2 *}$ \\ ${ }^{1}$ Institute of Nutrition and Food Safety, Chinese Center for Disease Control and Prevention, Beijing 100050, \\ People's Republic of China \\ ${ }^{2}$ National Institute of Nutrition and Seafood Research (NIFES), N-5817 Bergen, Norway \\ ${ }^{3}$ Department of Biomedicine, University of Bergen, Bergen, Norway \\ (Submitted 10 April 2011 - Final revision received 16 November 2011 - Accepted 16 November 2011 - First published online 6 January 2012)
}

\section{Abstract}

Dietary intervention studies to assess the cardioprotective effects of oily fish are scarce in China. The present study aimed to examine the effects of the oily fish, Norwegian salmon, herring and local farmed pompano (Trachinotus ovatus) on CVD risk markers when included in the Chinese diet. In this 8-week, parallel-arm, randomised intervention study, 126 Chinese women with hypertriacylglycerolaemia, aged 35-70 years, were assigned to four groups to consume an experimental lunch containing $80 \mathrm{~g}$ fillets of either one of three oily fish or a mix of commonly eaten meats (pork/chicken/beef/lean fish) for $5 \mathrm{~d} /$ week. The results showed that inclusion of the three oily fish significantly increased the intake of $n-3$ long-chain PUFA (LC-PUFA) while decreasing the dietary $n-6: n-3$ PUFA ratio. Compared to the control group, significant increases of DHA, EPA + DHA and total $n-3$ PUFA in plasma choline phosphoglyceride were observed in the three oily fish groups. Plasma TAG levels were significantly reduced only in the salmon and herring groups. When compared to the baseline level, the three oily fish diets significantly decreased serum concentrations of TAG, apoB, apoCII and apoCIII, but only the salmon and herring diets significantly lowered TNF- $\alpha$ and raised adiponectin levels in serum. The salmon diet additionally decreased the serum concentration of IL-6. To conclude, dietary inclusion of salmon, herring and pompano as oily fish can effectively increase serum $n$-3 LC-PUFA content and are associated with favourable biochemical changes in dyslipidaemic middle-aged and elderly Chinese women, and these beneficial effects are mainly associated with $n$-3 LC-PUFA contents.

Key words: Dietary intervention study: Oily fish: Salmon: Herring: Pompano: $\boldsymbol{n}$-3 Fatty acids: CVD biomarkers

It is estimated that chronic diseases will account for $75 \%$ of all deaths worldwide and that approximately half of the deaths are attributable to $\mathrm{CVD}^{(1)}$. Epidemiologically, the strong cross-sectional associations between CVD and dietary pattern have been widely accepted ${ }^{(2)}$. The Western dietary pattern, characterised by high intakes of red meat, sugary desserts, high-fat foods and refined grains with high $n-6: n-3$ fatty acid ratios, has been associated with a greater risk of CVD incidence $^{(3)}$. By contrast, the traditional Chinese diet, which typically has a high content of vegetables and whole grains, is regarded to be a relatively healthier dietary pattern compared to the Western diet. However, with rapid economic development and lifestyle changes, a dietary transition occurred in China leading to the increased consumption of vegetable oils and animal foods, resulting in increases of total fat intake and of the $n-6: n-3$ fatty acid ratio ${ }^{(4,5)}$. Today, CVD has also become the principal cause of mortality and morbidity among adult people in China. In 2010, the Chinese Ministry of Health reported that the death rate for cerebrovascular disease and CHD is 255/100 000 in urban areas, and women contributed to higher rates than men $(44 \cdot 1 v$. $40 \cdot 1 \%$, respectively) ${ }^{(6)}$. Despite the advance of aggressive medical therapies that improve clinical symptoms and slow disease progression, CVD continues to cause disability in China. Therefore, disease prevention initiatives are being encouraged including nutritional approaches to consuming more healthy foods.

There is a considerable body of evidence indicating that inclusion of fish, particularly oily fish, in the diet is protective against $\mathrm{CVD}^{(7-9)}$. The beneficial effects of oily fish in reducing the risk of CVD are mainly related to its high content of $n-3$ long-chain PUFA (LC-PUFA), particularly EPA and DHA ${ }^{(10)}$ The proposed mechanisms by which $n-3$ LC-PUFA protects

Abbreviations: AA, arachidonic acid; CPG, choline phosphoglyceride; HDL-C, HDL-cholesterol; LC-PUFA, long-chain PUFA; LDL-C, LDL-cholesterol; TC, total cholesterol.

*Corresponding author: Dr Z.-Y. Du, fax +47 55905299, email zdu@nifes.no 
against CVD is related to the incorporation of EPA and DHA into membrane phospholipids, thereby changing the membrane properties and leading to various beneficial effects, including lowering blood pressure, reducing serum TAG, thrombotic tendency, inflammation and improving endothelial function $^{(11-13)}$. Therefore, oily fish has been widely recommended to improve the present 'unhealthy dietary pattern'. Based on this, we assumed that inclusion of oily fish in the modern Chinese diet could also play beneficial roles in reducing CVD risk markers, and this had been partly verified by our recent study ${ }^{(14)}$. In this 8 -week dietary intervention study, we found that by including Norwegian Atlantic salmon at the rate of $500 \mathrm{~g} /$ week in lunch, serum EPA and DHA concentrations were significantly elevated, whereas serum TAG and IL-6 decreased in dyslipidaemic adult Chinese men, as compared to when pork/chicken/beef or lean fishmeal was consumed as a control.

However, it is of note that 'oily fish' is only a generic name for a number of fish species, such as salmon, herring, tuna, mackerel and sardine, and the $n$ - 3 LC-PUFA content differs between fish species. In the majority of human dietary intervention trials using oily fish, only a single species of oily fish $^{(15,16)}$, or a mixture of several oily fish, was involved ${ }^{(11,17)}$. Therefore, information comparing the beneficial effects between different oily fish species is very limited. Although several oily fish such as salmon, trout, herring and tuna have been verified to offer protection from CVD risk, the geographical distribution of these oily fish is limited. In China, few oily fish species are commonly accepted by consumers and this is mainly due to two reasons: (1) in general, most oily fish live in cold water at high altitudes, whereas few oily fish live in warm water at relatively low altitudes. Thus, when compared with some countries in the northern hemisphere, for example Norway and Canada, relatively fewer oily fish species are available near the coast of China; (2) traditionally, most Chinese believe that the health benefits of fish consumption are due to its high protein and low fat content. Hence, lean seafood and fresh-water fish such as carp are favoured over oily fish.

However, the increasing CVD incidence in China as well as mounting evidence for the health benefits of the marine $n-3$ LC-PUFA supplied by oily fish points to the need for assessing the effects on CVD risk markers of local, affordable and acceptable oily fish species in comparison with those usually consumed in western countries in high-risk Chinese subjects. In addition, if some local oily fish species are found to have comparable benefits as those well-accepted oily fish in western countries, it could provide more food choices to the common Chinese population. In the present study, we chose to use a local farmed marine oily fish, pompano (Trachinotus ovatus), which contains about $10 \%$ fat in fillet, almost equal to that of the typical oily fish species salmon and herring, and we assumed that it could also play a beneficial role in reducing CVD risk markers.

There is abundant evidence that pre-menopausal oestrogen levels inhibit the progression of CVD, and that after menopause, CVD becomes more invasive with the involvement of inflammation and the appearance of calcified atheromas in the vessel wall ${ }^{(18)}$. Therefore, when compared with adult men, middle-aged and elderly women are more seriously affected by $\mathrm{CVD}^{(6)}$, and have more specialised traits in physiology, food selection, living habits and the amount of attention paid to their health. Thus, we hypothesised that this group could also benefit from the dietary inclusion of oily fish in the primary prevention of CVD. The purpose of the present study was to investigate and compare the CVDprevention effects of different oily fish in middle-aged and elderly Chinese women. To that end, an 8-week, parallelarm and randomised dietary intervention study was performed in 126 women with hypertriacylglycerolaemia (aged 35-70 years), using salmon, herring or pompano compared to the mix of commonly eaten meats (pork/chicken/beef/lean fish) for $5 \mathrm{~d} /$ week. To the best of our knowledge, this is the first dietary intervention trial involving Chinese local farmed oily fish in middle-aged and elderly Chinese women.

\section{Subjects and methods}

\section{Subjects}

The present study was conducted according to the guidelines laid down in the Declaration of Helsinki. All procedures involving human subjects were approved by the Ethical Committee of the Institute of Nutrition and Food Safety, Chinese Center for Disease Control and Prevention (INFS 20100301) and registered at the Chinese Clinical Trial Registry (ChiCTR-TRC10001164). Written informed consent was obtained from all subjects after they had received both oral and written information about the study. We recruited adult women from the community health service centre in Chaoyang District, Beijing. Women who were interested in the study contacted the staff of the research group and presented their former medical examination records and were interviewed by investigators using screening questionnaires, which included questions on basic health status and eating habits. Those who met the inclusion criteria were invited to take part in a physical examination. Eligible participants were women in apparently relatively good physical and cognitive health status, aged between 35 and 70 years, with serum levels of TAG $\geq 1.70 \mathrm{mmol} / 1$. Exclusion criteria were: (1) diagnosed diabetes; (2) myocardial or cerebral infarction or cerebral haemorrhage; (3) liver or other endocrine dysfunction; (4) receiving hypolipidaemic therapy or any other medication known to interfere with lipid metabolism; (5) intake of $n-3$ fatty acid supplements or hypolipidaemic function foods; (6) heavy smoking $(\geq 20$ cigarettes/d) or consuming more than seven alcohol-containing drinks per week.

\section{Study design}

We performed a randomised, parallel, 8-week intervention study in middle-aged and elderly women with hypertriacylglycerolaemia. The subjects were randomised to consume the experimental lunch meal with $80 \mathrm{~g}$ fillet of salmon, herring or pompano for $5 \mathrm{~d}$ /week. The same weight of a mix of commonly eaten meats was used as the control meals comprising 
two days of pork meal, one day of beef, one day of chicken and one day of lean fishmeals, from Monday to Friday each week.

The lunch meal plan included ten different menus with usually consumed foods such as tomato, potato, Chinese cabbage, spinach, celery, carrot, onion, cucumber, mushroom, bean curd, egg, etc. The cooking oil habitually used by most of the subjects was peanut oil. The four test lunch meals were common in almost all aspects other than the type of animal meat. During the 2 -week run-in and the 8 -week intervention period, all subjects were encouraged to maintain their usual food choice and living style except for eating the test lunch in four different venues in their living community. The project staff and nurses from the community health service unit took responsibility for the distribution of the test meal and recording the compliance. A qualified fast-food company prepared the lunches according to a menu designed by project investigators and their invited nutritionists. The $4 \mathrm{~d}, 24 \mathrm{~h}$ dietary record was undertaken by trained staff at the beginning and the end of the study with the aid of an electric food scale and some food models such as reference bowls, cups, spoons, etc. The intake of total energy, macronutrients and fatty acids was calculated by using a Chinese Food Composition Table (version 2002 and supplement version 2004).

\section{Anthropometric measures and blood pressure}

The height of each volunteer was measured at baseline. Participants' body weight and waist circumference were measured after $12 \mathrm{~h}$ fasting at both the start and the end of study. The blood pressure of each participant was also measured using an automated manometer (Omron HEM 7000) at the start and end of the study.

\section{Laboratory measurements}

The $12 \mathrm{~h}$ fasting blood samples of subjects were collected by venepuncture at the beginning of the study (week 0) and after the intervention period (week 8) ended. Serum and plasma were prepared by centrifugation at $1500 \mathrm{~g}$ for $15 \mathrm{~min}$ at $4^{\circ} \mathrm{C}$ within $1 \mathrm{~h}$ of collection and were stored at $-70^{\circ} \mathrm{C}$ for batch analysis of the variables within 6 months.

Plasma total lipids were extracted using the method of Folch et $a l .{ }^{(19)}$ by homogenising the samples in chloroform and methanol (2:1, v/v) containing $0 \cdot 01 \%$ butylated hydroxytoluene as an antioxidant under $\mathrm{N}_{2}$. Phosphoglyceride classes were separated by TLC on silica gel plates using the developing solvents chloroform, methanol and water (60:30:4, v/v) containing $0.01 \%$ butylated hydroxytoluene. The bands were detected by spraying the developed plate with a methanolic solution of 2,7 dichloro-fluorescein $(0.01 \% \mathrm{w} / \mathrm{v})$ and visualised under UV light. They were then compared to the lecithin standard provided by Beijing Chemical Reagent Limited. The choline phosphoglyceride (CPG) band was scraped from the silica plate and transferred to a tube, sealed and methylated with $15 \%$ acetyl chloride in methanol by heating at $70^{\circ} \mathrm{C}$ for $3 \mathrm{~h}$ under $\mathrm{N}_{2}$. The resulting fatty acid methyl esters were separated by a gas chromatograph (Shimadzu GC 14B) fitted with a capillary column of $100 \mathrm{~m} \times 0.25 \mathrm{~mm}$ inner diameter, $0.2 \mu \mathrm{m}$ film, CP-SIL 88 (VARIAN). Helium was used as a carrier gas at a flow rate of $2 \mathrm{ml} / \mathrm{min}$. The split ratio, and injector and detector temperatures were $40: 1,260$ and $260^{\circ} \mathrm{C}$, respectively. The oven programme had an initial temperature of $140^{\circ} \mathrm{C}$, which was held for $5 \mathrm{~min}$ and subsequently increased to $240{ }^{\circ} \mathrm{C}$ at $4^{\circ} \mathrm{C} / \mathrm{min}$. Fatty acid methyl esters were identified by comparison with retention times of commercially available fatty acid standards (catalogue no. 47885-U, Supelco, Inc.) and peak areas were quantified with the use of a computer data system (CBM-101 workstation; Shimadzu).

Serum total cholesterol (TC), HDL-cholesterol (HDL-C), TAG, LDL-cholesterol (LDL-C) and glucose levels were measured using a Hitachi 7600 automated biochemical analyser (Hitachi Limited) with enzymatic assay kits from Leadman (Leadman Biochemistry Company Limited). ApoAI, apoB, apoCII, apoCIII and apoE were measured by the rate of light scatter resulting from an immunoprecipitation reaction with the Hitachi 7600 . The intra- and inter-assay CV\% were from 0.3 to $2.0 \%$, and from 0.5 to $2.6 \%$. Insulin, IL-6 and TNF- $\alpha$ were measured by using a $\gamma$-counter with radioimmunological assay kits (North Biotech Company). The intra- and inter-assay $\mathrm{CV} \%$ were below $5 \%$ and $10 \%$. Levels of both the intercellular adhesion molecule-1 and the vascular cell adhesion molecule-1 were measured using ELISA kits (R\&D Systems, Inc.). The level of high-sensitivity C-reactive protein level was measured by an immunoturbidity kit (Diasys Diagnostic Systems Company Limited). The intra- and inter-assay CV\% were below 1.7 and $2.6 \%$. Adiponectin was measured by the ELISA method (Adipo-Biotech) and the intra- and inter-assay $\mathrm{CV} \%$ were below 4 and $10 \%$.

Insulin sensitivity was estimated using the homeostasis model assessment of insulin resistance, which was calculated using the following formula:

Homeostatic assessment model

$$
=\text { fasting plasma insulin }(\mu \mathrm{U} / \mathrm{ml})
$$

$\times$ fasting plasma glucose $(\mathrm{mmol} / \mathrm{l}) / 22 \cdot 5$.

\section{Statistical analyses}

From reported studies that showed convincing changes in lipid profile with oily fish intake and supplementation of high content of $n$-3 LC-PUFA ${ }^{(10)}$, we predicted that a sample size of twenty-nine participants in each group would be needed to detect a statistically significant difference in serum TAG within and between groups with a power of $80 \%$ and a two-sided $\alpha$ of $0 \cdot 05$. Data describing the characteristics of the subjects are summarised as the means and standard deviations except for some categorical variables and frequencies that are presented as percentages. The Kolmogorov-Smirnov test was used for distribution determination. Data of biochemical outcome are expressed as means and standard errors of the mean or median values and quartile ranges. The oneway ANOVA plus least significant difference test was used to compare differences between groups. The Kruskal-Wallis 
test followed by the Mann-Whitney $U$ test was used for intergroup comparisons of skewed data, while categorical variables and frequencies were analysed by the $\chi^{2}$ test. Comparisons between the values of continuous variables before and after the intervention within each test group were made with the paired Student's $t$ test; and the Wilcoxon rank sum test was used to determine intragroup differences for the skewed distribution data. Data were analysed using mixed-model ANOVA for treatment effects. A $P$ value below 0.05 was regarded as significant. All statistical analyses were performed with the use of SPSS (version 13.0 for Windows; SPSS, Inc.).

\section{Results}

\section{Participants and diet intake}

A total of 131 women met the recruitment criteria and participated in the study, with thirty-three in the salmon group, thirty-two in the herring group, thirty-three in the pompano group and thirty-three in the control group. During the intervention period, three participants dropped out of the herring group (two participants because they had to leave Beijing to attend their relative's funeral, one developed high fever at the end of the study and could not participate in the final examination), one participant dropped out of the salmon group because her husband was hospitalised after suffering a stroke, and one participant discontinued her participation in the control group because she moved away from our eating venue. Therefore, the final sample number for statistical analyses was thirty-two, twenty-nine, thirty-three and thirtytwo for the salmon, herring, pompano and control groups, respectively. Baseline parameters of the four groups are shown in Table 1 and there were no significant differences between groups at the beginning of the study. Although oily fish is not a food that is typical in the Chinese diet, the subjects were satisfied with the designed test meals and all subjects in each group came to the venue to eat the test lunch according to the study requirements. There was no unfavourable impact on the participants' basic health-related parameters, such as $\mathrm{Hb}$ albumin, detected during the intervention.

As shown in Table 2, compared to the baseline level (week 0), the four intervention treatments significantly increased participant intake of protein, arachidonic acid (AA), EPA and DHA; however, significant increases in total PUFA, and total $n-3$ PUFA with a corresponding significant decrease in the $n-6: n-3$ PUFA ratio were only observed in the three oily fish groups. After the 8-week intervention, the average intakes of energy, fat, protein, carbohydrate, cholesterol, MUFA, $n$-6 PUFA, linoleic acid and $\alpha$-linolenic acid were comparable between the four test groups. However, compared to the control group, the three oily fish groups had significantly increased AA intake $(P<0 \cdot 01)$, and also very significantly increased intakes of $n$-3 LC-PUFA, including EPA, DHA and EPA + DHA $(P<0 \cdot 01)$. Meanwhile, the $n-6: n-3$ PUFA ratio was very significantly reduced in the three oily fish groups compared to that in the control group $(P<0 \cdot 01)$. Within the three oily fish groups, the pompano group had significantly lower intakes of EPA $(P<0.01)$ but higher AA than in the salmon and herring groups $(P<0 \cdot 01)$. The salmon group showed significantly higher $n-3$ PUFA and DHA $(P<0 \cdot 01)$, lower EPA $(P<0 \cdot 01)$, but similar EPA + DHA and AA intake ( $P=0.389, P=0.365)$ when compared to that in the herring group. The $n-6: n-3$ PUFA ratio in the salmon and herring groups was comparable $(P=0 \cdot 218)$, but significantly lower than that in the pompano group $(P<0.01)$. In addition, the intake of SFA was also significantly lower in both the salmon and herring groups than in the control group $(P<0 \cdot 01$, $P=0 \cdot 014)$, but there was no significant difference seen between the pompano and control groups $(P=0.063)$. In short, dietary inclusion of the three oily fish mainly increased the $n$-3 LC-PUFA intake and decreased the $n-6: n-3$ PUFA ratio, but with different degrees as salmon $\geq$ herring $>$ pompano.

Table 1. Baseline characteristics of participants (Mean values and standard deviations or percentages)

\begin{tabular}{|c|c|c|c|c|c|c|c|c|}
\hline & \multicolumn{2}{|c|}{ Salmon (n 32) } & \multicolumn{2}{|c|}{ Herring (n 29) } & \multicolumn{2}{|c|}{ Pompano (n 33) } & \multicolumn{2}{|c|}{ Control (n 32) } \\
\hline & Mean & SD & Mean & SD & Mean & SD & Mean & SD \\
\hline Age (years) & 54.9 & $7 \cdot 7$ & $55 \cdot 6$ & $8 \cdot 6$ & $56 \cdot 5$ & $3 \cdot 8$ & $56 \cdot 3$ & $6 \cdot 6$ \\
\hline Height (cm) & 157.5 & $5 \cdot 3$ & $157 \cdot 4$ & 4.4 & $158 \cdot 0$ & $5 \cdot 1$ & $158 \cdot 6$ & 4.5 \\
\hline Weight (kg) & 65.4 & $7 \cdot 1$ & 68.5 & $8 \cdot 3$ & 66.5 & $8 \cdot 8$ & 65.4 & $10 \cdot 2$ \\
\hline $\mathrm{BMI}\left(\mathrm{kg} / \mathrm{m}^{2}\right)$ & $26 \cdot 4$ & $3 \cdot 1$ & $27 \cdot 7$ & $3 \cdot 2$ & $26 \cdot 6$ & 3.0 & $26 \cdot 0$ & $4 \cdot 0$ \\
\hline WC (cm) & $83 \cdot 6$ & $6 \cdot 9$ & 85.5 & $8 \cdot 7$ & $84 \cdot 4$ & $6 \cdot 4$ & 84.4 & $9 \cdot 5$ \\
\hline $\mathrm{Hb}(\mathrm{g} / \mathrm{l})$ & $138 \cdot 2$ & $9 \cdot 7$ & $136 \cdot 8$ & $13 \cdot 1$ & $137 \cdot 8$ & $8 \cdot 0$ & $136 \cdot 5$ & $11 \cdot 8$ \\
\hline $\mathrm{SBP}(\mathrm{mmHg})$ & $128 \cdot 8$ & $17 \cdot 2$ & $129 \cdot 8$ & $16 \cdot 0$ & 128.4 & $13 \cdot 6$ & $132 \cdot 5$ & $15 \cdot 4$ \\
\hline DBP $(\mathrm{mmHg})$ & $80 \cdot 2$ & $10 \cdot 8$ & $79 \cdot 2$ & $7 \cdot 8$ & $80 \cdot 3$ & $8 \cdot 7$ & $82 \cdot 6$ & $6 \cdot 1$ \\
\hline Hypertension (\%) & \multicolumn{2}{|c|}{$25 \cdot 0$} & \multicolumn{2}{|c|}{$31 \cdot 0$} & \multicolumn{2}{|c|}{$21 \cdot 2$} & \multicolumn{2}{|c|}{$28 \cdot 1$} \\
\hline Overweight (\%) & \multicolumn{2}{|c|}{$46 \cdot 9$} & \multicolumn{2}{|c|}{$48 \cdot 3$} & \multicolumn{2}{|c|}{$51 \cdot 5$} & \multicolumn{2}{|c|}{$31 \cdot 3$} \\
\hline Obesity (\%) & \multicolumn{2}{|c|}{$25 \cdot 0$} & \multicolumn{2}{|c|}{37.9} & \multicolumn{2}{|c|}{$27 \cdot 3$} & \multicolumn{2}{|c|}{34.4} \\
\hline \multicolumn{9}{|l|}{ Education (\%) } \\
\hline None to middle school & \multicolumn{2}{|c|}{$31 \cdot 2$} & \multicolumn{2}{|c|}{34.5} & \multicolumn{2}{|c|}{$24 \cdot 2$} & \multicolumn{2}{|c|}{34.4} \\
\hline Junior college & \multicolumn{2}{|c|}{$59 \cdot 4$} & \multicolumn{2}{|c|}{$55 \cdot 2$} & \multicolumn{2}{|c|}{$66 \cdot 7$} & \multicolumn{2}{|c|}{$56 \cdot 3$} \\
\hline University or more & \multicolumn{2}{|c|}{$9 \cdot 4$} & \multicolumn{2}{|c|}{$10 \cdot 3$} & \multicolumn{2}{|c|}{$9 \cdot 1$} & \multicolumn{2}{|c|}{$9 \cdot 4$} \\
\hline
\end{tabular}

WC, waist circumference; SBP, systolic blood pressure; DBP, diastolic blood pressure. 
Table 2. Macronutrient and fatty acid intake at baseline and during the intervention period $\dagger$

(Mean values with their standard errors)

\begin{tabular}{|c|c|c|c|c|c|c|c|c|c|c|}
\hline & \multicolumn{2}{|c|}{$\begin{array}{l}\text { Baseline ( } n \text { 126) } \\
\quad \text { Week } 0\end{array}$} & \multicolumn{2}{|c|}{$\begin{array}{l}\text { Salmon } \\
\text { Week } 8\end{array}$} & \multicolumn{2}{|c|}{$\begin{array}{l}\text { Herring } \\
\text { Week } 8\end{array}$} & \multicolumn{2}{|c|}{$\begin{array}{l}\text { Pompano } \\
\text { Week } 8\end{array}$} & \multicolumn{2}{|c|}{$\begin{array}{l}\text { Control } \\
\text { Week } 8\end{array}$} \\
\hline & Mean & SEM & Mean & $\overline{\text { SEM }}$ & Mean & SEM & Mean & SEM & Mean & $\overline{\text { SEM }}$ \\
\hline Energy $(\mathrm{kJ} / \mathrm{d})$ & 6668.5 & $108 \cdot 9$ & $6909 \cdot 2$ & $122 \cdot 4$ & $7019 \cdot 8$ & $157 \cdot 5$ & $6997 \cdot 8$ & $212 \cdot 0$ & 7231.6 & 192.5 \\
\hline Protein $(\mathrm{g} / \mathrm{d})$ & 59.5 & 1.4 & $69 \cdot 7^{\star \star}$ & 1.7 & $71 \cdot 8^{\star *}$ & 2.4 & $72 \cdot 8^{\star \star}$ & $2 \cdot 8$ & $76 \cdot 9^{\star \star}$ & $2 \cdot 1$ \\
\hline Carbohydrates (g/d) & 220.5 & 4.8 & 214.3 & $5 \cdot 0$ & 218.0 & $6 \cdot 5$ & $225 \cdot 6$ & 9.5 & 234.9 & $7 \cdot 6$ \\
\hline Fat $(g / d)$ & 57.6 & 1.3 & 59.5 & 1.7 & $60 \cdot 1$ & 1.9 & 58.6 & 1.5 & $59 \cdot 4$ & $2 \cdot 1$ \\
\hline Cholesterol $(\mathrm{mg} / \mathrm{d})$ & 294.5 & $10 \cdot 7$ & 293.1 & $16 \cdot 0$ & $300 \cdot 6$ & $19 \cdot 0$ & $287 \cdot 6$ & $19 \cdot 4$ & $315 \cdot 2$ & $20 \cdot 9$ \\
\hline SFA $(g / d)$ & $13 \cdot 1$ & 0.4 & $12 \cdot 2^{\mathrm{a}}$ & 0.5 & $13 \cdot 5^{a, b}$ & 0.6 & $14 \cdot 0^{\mathrm{b}, \mathrm{c}}$ & 0.4 & $15 \cdot 4^{\star c}$ & 0.6 \\
\hline $\operatorname{MUFA}(\mathrm{g} / \mathrm{d})$ & $20 \cdot 7$ & 0.6 & $21 \cdot 0$ & 0.6 & $22 \cdot 6$ & 0.9 & $20 \cdot 7$ & 0.6 & $22 \cdot 7$ & 0.9 \\
\hline PUFA $(g / d)$ & $15 \cdot 6$ & 0.5 & $17 \cdot 6^{*}$ & 0.5 & $17 \cdot 5^{*}$ & 0.6 & $17 \cdot 6^{*}$ & 0.6 & $16 \cdot 6$ & 0.6 \\
\hline$n-6$ Fatty acids $(\mathrm{g} / \mathrm{d})$ & 14.4 & 0.4 & 14.4 & 0.4 & 14.8 & 0.6 & 15.5 & 0.5 & 15.5 & 0.6 \\
\hline LA $(18: 2 n-6)(g / d)$ & $14 \cdot 3$ & 0.4 & $14 \cdot 2$ & 0.4 & $14 \cdot 6$ & 0.6 & $15 \cdot 3$ & 0.5 & $15 \cdot 4$ & 0.6 \\
\hline AA $(20: 4 n-6)(\mathrm{mg} / \mathrm{d})$ & $31 \cdot 1$ & $2 \cdot 4$ & $69 \cdot 0^{* \star b}$ & $2 \cdot 6$ & $76 \cdot 9^{\star \star b}$ & $6 \cdot 8$ & $105 \cdot 7^{\star \star c}$ & 2.5 & $49 \cdot 1^{* * a}$ & 4.9 \\
\hline$n-3$ Fatty acids (g/d) & 1.2 & 0.1 & $3 \cdot 2^{\star * d}$ & 0.1 & $2 \cdot 8^{\star \star c}$ & 0.1 & $2 \cdot 1^{\star * b}$ & 0.1 & $1 \cdot 1^{\mathrm{a}}$ & 0.1 \\
\hline $\operatorname{ALA}(18: 3 n-3)(\mathrm{g} / \mathrm{d})$ & $1 \cdot 1$ & 0.1 & $1 \cdot 2$ & 0.1 & 1.0 & 0.1 & 0.9 & $0 \cdot 1$ & 1.0 & 0.1 \\
\hline $\operatorname{EPA}(20: 5 n-3)(\mathrm{mg} / \mathrm{d})$ & $13 \cdot 8$ & $2 \cdot 1$ & $613 \cdot 8^{\star \star c}$ & $2 \cdot 6$ & $701 \cdot 8^{\star \star d}$ & 4.0 & $137 \cdot 2^{\star \star b}$ & $3 \cdot 3$ & $28 \cdot 8^{\star \star a}$ & $8 \cdot 4$ \\
\hline DHA $(22: 6 n-3)(\mathrm{mg} / \mathrm{d})$ & $30 \cdot 8$ & 1.9 & $1072 \cdot 9^{\star \star d}$ & 4.2 & $972 \cdot 5^{\star \star c}$ & $2 \cdot 7$ & $935 \cdot 0^{* * b}$ & $5 \cdot 6$ & $58 \cdot 4^{\star \star a}$ & $7 \cdot 8$ \\
\hline $\mathrm{EPA}+\mathrm{DHA}(\mathrm{mg} / \mathrm{d})$ & 44.5 & 3.5 & $1686 \cdot 7^{\star \star c}$ & 6.5 & $1674 \cdot 3^{\star \star c}$ & $5 \cdot 2$ & $1072 \cdot 2^{\star \star b}$ & 8.6 & $87 \cdot 2^{\star \star a}$ & $15 \cdot 6$ \\
\hline$n-6: n-3$ PUFA & 17.9 & 0.9 & $4 \cdot 6^{\star \star a}$ & 0.1 & $5 \cdot 4^{\star \star a}$ & 0.1 & $7 \cdot 3^{\star \star b}$ & 0.2 & $15 \cdot 1^{\mathrm{c}}$ & 0.8 \\
\hline
\end{tabular}

LA, linoleic acid; AA, arachidonic acid; ALA, $\alpha$-linolenic acid.

a,b,c,d Mean values within a row with unlike superscript letters were significantly different $(P<0.05)$.

Mean values were significantly different from those of week 0 : ${ }^{\star} P<0.05$, ${ }^{\star \star} P<0.01$.

†The post hoc comparison between four intervention groups ( 8 weeks) was carried out using the least significant difference multiple comparison test (SPSS 13.0; SPSS, Inc.).

\section{Plasma choline phosphoglyceride fatty acid composition}

As shown in Table 3, at baseline, all CPG fatty acids were comparable between groups, except the salmon group which had a significantly higher level of EPA than the pompano $(P=0 \cdot 010)$ and control groups $(P=0 \cdot 022)$. After the 8 -week intervention, the percentage of total $n-6$ PUFA was significantly decreased in all groups, whereas the percentages of total $n-3$ PUFA, DHA and EPA + DHA were only significantly increased in the three oily fish groups $(P<0 \cdot 01)$. Accordingly, the $n-6: n-3$ PUFA ratio decreased significantly in the three oily fish groups $(P<0 \cdot 01)$, but not in the control group. Different from DHA, the significantly increased EPA was only observed in the salmon and herring groups, but not in the pompano group. To compare the effects of the three oily fish diets on increasing plasma $n-3$ PUFA, the net increased values of EPA, DHA, EPA + DHA and total $n-3$ PUFA are presented in Table 7. It showed that the net increase of EPA in plasma CPG in the salmon and herring groups was significantly higher than in the control group $(P=0.029, P<0.01)$. There was no significant difference between the three oily fish groups. The net increase of DHA, EPA + DHA and total $n-3$ PUFA in the three oily fish groups was significantly higher than that in the control group $(P<0 \cdot 01)$, and there were no significant differences between the three oily fish groups.

\section{Serum lipid profile}

Serum lipid values are presented in Table 4. After the 8-week intervention, serum concentrations of TAG, apoB, apoCII and apoCIII decreased significantly in the groups consuming salmon $(P<0.01, \quad P=0.049, \quad P=0.021, \quad P=0.036)$, herring
$(P<0.01, \quad P=0.043, \quad P=0.020, \quad P<0.01)$ and pompano $(P<0.01, P=0.049, P=0.016, P=0.011)$, but not in the control group. There were no significant intra-changes in serum concentrations of TC, HDL-C, LDL-C, apoAI and apoE observed in any of the groups. To compare the effects of the three oily fish diets in reducing serum lipids, the net decreased values of TAG, apoB, apoCII and apoCIII in the three oily fish and control groups are presented in Table 7 . The net TAG reduction in the salmon and herring groups were comparable and both were significantly larger than that in the control group $(P=0.010, P=0.019)$. However, the pompano group showed a non-significant difference when compared to the other groups. There were no significant differences between groups in the net decreases of apoB, apoCII and apoCIII. However, of note, we found that there was a tendency for the decreased serum lipid values to be positively related to the dietary EPA + DHA intake and negatively related to the dietary $n$-6:n-3 PUFA ratio, particularly in the case of TAG, apoB and apoCII. With these parameters, the pompano group showed the lowest effects among the three oily fish groups, accompanied by its lowest EPA + DHA intake and highest $n-6: n-3$ PUFA ratio.

\section{Serum inflammation-related markers}

As to the inflammation-related markers shown in Table 5, dietary inclusion of the three oily fish did not significantly affect serum concentrations of high-sensitivity C-reactive protein, intercellular adhesion molecule-1 or vascular cell adhesion molecule-1. However, significant reduction of serum IL-6 and TNF- $\alpha$ was found in the salmon group $(P=0.037$, $P=0.049$ ), while only a decrease in TNF- $\alpha$ levels was 
Table 3. Plasma choline phosphoglyceride fatty acid levels in the four groups at the beginning and end of the intervention period $\dagger$

(Mean values with their standard errors)

\begin{tabular}{|c|c|c|c|c|c|c|c|c|}
\hline & \multicolumn{2}{|c|}{ Salmon } & \multicolumn{2}{|c|}{ Herring } & \multicolumn{2}{|c|}{ Pompano } & \multicolumn{2}{|c|}{ Control } \\
\hline & Mean & SEM & Mean & SEM & Mean & SEM & Mean & SEM \\
\hline \multicolumn{9}{|l|}{ Total SFA } \\
\hline 0 week & $45 \cdot 6$ & 0.6 & $46 \cdot 2$ & 0.7 & $45 \cdot 4$ & 0.6 & $46 \cdot 2$ & 0.8 \\
\hline 8 week & $46 \cdot 3$ & 0.5 & 45.9 & 0.8 & $44 \cdot 8$ & 0.9 & $47 \cdot 2$ & 0.6 \\
\hline \multicolumn{9}{|c|}{ Total MUFA } \\
\hline 0 week & $7 \cdot 4$ & 0.2 & $7 \cdot 4$ & 0.2 & $7 \cdot 2$ & 0.1 & $7 \cdot 2$ & 0.2 \\
\hline 8 week & $7 \cdot 7$ & $0 \cdot 1$ & $7 \cdot 8$ & 0.2 & 7.4 & 0.4 & 7.5 & 0.2 \\
\hline \multicolumn{9}{|c|}{ Total PUFA } \\
\hline 0 week & $43 \cdot 0$ & 0.6 & 41.3 & $1 \cdot 1$ & $43 \cdot 1$ & 0.6 & $42 \cdot 6$ & 0.8 \\
\hline 8 week & $40 \cdot 9$ & 0.7 & 41.6 & 0.9 & $42 \cdot 3$ & 0.7 & $40 \cdot 6$ & 0.6 \\
\hline \multicolumn{9}{|c|}{ Total $n-6$ PUFA } \\
\hline 0 week & 37.5 & 0.5 & $36 \cdot 3$ & $1 \cdot 0$ & $38 \cdot 2$ & 0.6 & $37 \cdot 6$ & 0.7 \\
\hline 8 week & $33 \cdot 4^{\star *}$ & 0.6 & $33 \cdot 5^{\star \star}$ & 0.7 & $34.9^{\star *}$ & 0.6 & $35 \cdot 4^{\star \star}$ & 0.6 \\
\hline \multicolumn{9}{|c|}{ LA $(18: 2 n-6)$} \\
\hline 0 week & 24.5 & 0.4 & $24 \cdot 1$ & 0.7 & 24.9 & 0.5 & $24 \cdot 8$ & 0.5 \\
\hline 8 week & $21 \cdot 6$ & 0.4 & $22 \cdot 3$ & 0.4 & $22 \cdot 4$ & $0 \cdot 6$ & $23 \cdot 2$ & 0.4 \\
\hline \multicolumn{9}{|c|}{ AA $(20: 4 n-6)$} \\
\hline 0 week & $9 \cdot 9$ & 0.4 & 8.9 & 0.4 & $10 \cdot 0$ & 0.4 & $9 \cdot 6$ & 0.4 \\
\hline 8 week & $8 \cdot 7^{\star}$ & 0.3 & $8 \cdot 1$ & 0.4 & $9 \cdot 0$ & 0.3 & $9 \cdot 0$ & 0.3 \\
\hline \multicolumn{9}{|c|}{ Total $n$-3 PUFA } \\
\hline 0 week & 5.5 & 0.3 & $5 \cdot 0$ & 0.3 & 4.9 & 0.2 & 4.9 & 0.2 \\
\hline 8 week & $8 \cdot 1^{\star \star}$ & 0.3 & $7 \cdot 7^{\star \star}$ & 0.4 & $7 \cdot 4^{\star \star}$ & 0.3 & $5 \cdot 3$ & 0.2 \\
\hline \multicolumn{9}{|c|}{ EPA $(20: 5 n-3)$} \\
\hline 0 week & $2 \cdot 6^{a}$ & 0.2 & $2 \cdot 4^{\mathrm{a}, \mathrm{b}}$ & 0.2 & $2 \cdot 0^{\mathrm{b}}$ & 0.1 & $2 \cdot 0^{\mathrm{b}}$ & 0.1 \\
\hline 8 week & $3 \cdot 6^{\star}$ & 0.3 & $3 \cdot 6^{\star \star}$ & 0.3 & $2 \cdot 9$ & 0.2 & $2 \cdot 2$ & 0.1 \\
\hline \multicolumn{9}{|c|}{ DHA $(22: 6 n-3)$} \\
\hline 0 week & $2 \cdot 3$ & 0.2 & $2 \cdot 2$ & 0.2 & $2 \cdot 4$ & 0.1 & $2 \cdot 4$ & 0.1 \\
\hline 8 week & $3.8^{\star \star}$ & 0.2 & $3 \cdot 5^{\star \star}$ & 0.3 & $3 \cdot 6^{* *}$ & 0.2 & 2.6 & 0.1 \\
\hline \multicolumn{9}{|c|}{$\mathrm{EPA}+\mathrm{DHA}$} \\
\hline 0 week & 4.9 & 0.2 & $4 \cdot 6$ & 0.3 & 4.4 & 0.2 & 4.4 & 0.2 \\
\hline 8 week & $7 \cdot 4^{\star \star}$ & 0.3 & $7 \cdot 1^{\star \star}$ & 0.4 & $6 \cdot 5^{\star *}$ & 0.3 & 4.8 & 0.2 \\
\hline \multicolumn{9}{|c|}{$n-6: n-3$ PUFA } \\
\hline 0 week & $7 \cdot 3$ & 0.4 & $7 \cdot 7$ & 0.4 & $8 \cdot 2$ & 0.3 & $8 \cdot 0$ & 0.3 \\
\hline 8 week & $4 \cdot 4^{\star \star}$ & 0.2 & $4 \cdot 5^{\star \star}$ & 0.3 & $5 \cdot 0^{\star \star}$ & 0.2 & $7 \cdot 0$ & 0.2 \\
\hline
\end{tabular}

LA, linoleic acid; AA, arachidonic acid.

${ }_{a, b}$ Mean values within a row with unlike superscript letters were significantly different $(P<0 \cdot 05)$.

Mean values were significantly different within the group before and after the 8-week trial: ${ }^{*} P<0.05$, ${ }^{* *} P<0.01$.

$\dagger$ The fatty acids are presented as \% of fatty acids.

observed in the herring group $(P=0.018)$ after intervention. No comparable changes in these inflammation markers were seen in the pompano and control groups. Accordingly, serum concentration of adiponectin, an anti-inflammation factor, was elevated in the salmon $(P=0.045)$ and herring groups $(P=0.037)$, but not in the pompano and control groups. The net effects of the three oily fish diets in reducing IL-6, TNF- $\alpha$ and increasing adiponectin are presented in Table 7. Although the mean of these parameters showed a big difference between the oily fish groups and the control group, there appeared to be no significant differences between groups due to large variation. However, the tendency for greater decreases in inflammation markers to be associated with higher dietary EPA + DHA intake and lower n-6:n-3 PUFA ratios was still observed.

\section{Insulin sensitivity-related parameters}

Serum concentrations of glucose, insulin and homeostasis model assessment of insulin resistance displayed no significant changes within each group after intervention (Table 6).

\section{Discussion}

Dietary inclusion of oily fish improves plasma fatty acid profile

The recent FAO report recommends $0.25 \mathrm{~g} / \mathrm{d}$ intake of $\mathrm{EPA}+\mathrm{DHA}$ for adult males and non-pregnant/non-lactating adult females ${ }^{(20)}$. However, in China, the average EPA + DHA intake is only $0.037 \mathrm{~g} / \mathrm{d}$ for the entire population and $0.069 \mathrm{~g} / \mathrm{d}$ in cities ${ }^{(5)}$, much lower than $0 \cdot 1-0.2 \mathrm{~g} / \mathrm{d}$ in North America and European countries ${ }^{(21,22)}$. In the present study, the baseline of dietary EPA + DHA intake was from 0.037 to $0.054 \mathrm{~g} / \mathrm{d}$ in the subjects of four groups (with an average of $0.045 \mathrm{~g} / \mathrm{d}$ ), much lower than the FAO recommendation. Moreover, the baseline of dietary $n-6: n-3$ PUFA ratio reached 18-20 (with an average of 17.9), similar to typical Western diets but much higher than $4-6$, which is recommended by the Chinese Nutrition Society ${ }^{(23)}$. The inclusion of salmon and herring significantly raised the intake of EPA + DHA to about $1.6 \mathrm{~g} / \mathrm{d}$ and sharply decreased the dietary $n-6: n-3$ PUFA ratio to about $5: 1$, which fits the recommendation. However, the EPA + DHA intake in the pompano group was 
Table 4. Serum lipid concentrations of the four groups at the beginning and end of the intervention period (Mean values with their standard errors)

\begin{tabular}{|c|c|c|c|c|c|c|c|c|}
\hline & \multicolumn{2}{|c|}{ Salmon } & \multicolumn{2}{|c|}{ Herring } & \multicolumn{2}{|c|}{ Pompano } & \multicolumn{2}{|c|}{ Control } \\
\hline & Mean & SEM & Mean & SEM & Mean & SEM & Mean & SEM \\
\hline \multicolumn{9}{|c|}{ TAG $(\mathrm{mmol} / \mathrm{l})$} \\
\hline 0 week & $2 \cdot 34$ & $0 \cdot 10$ & $2 \cdot 43$ & 0.16 & $2 \cdot 26$ & 0.11 & 2.44 & 0.09 \\
\hline 8 week & $1 \cdot 75^{\star *}$ & 0.11 & $1 \cdot 87^{\star \star}$ & 0.12 & $1 \cdot 77^{\star \star}$ & 0.11 & $2 \cdot 23$ & 0.15 \\
\hline \multicolumn{9}{|c|}{ TC $(\mathrm{mmol} / \mathrm{l})$} \\
\hline 0 week & $5 \cdot 38$ & 0.15 & $5 \cdot 38$ & 0.12 & $5 \cdot 54$ & $0 \cdot 16$ & $5 \cdot 32$ & 0.20 \\
\hline 8 week & $5 \cdot 23$ & 0.13 & $5 \cdot 38$ & 0.14 & 5.46 & 0.14 & $5 \cdot 26$ & 0.19 \\
\hline \multicolumn{9}{|c|}{ HDL-C (mmol/l) } \\
\hline 0 week & 1.36 & 0.04 & 1.30 & 0.04 & 1.29 & 0.05 & 1.24 & 0.05 \\
\hline 8 week & 1.34 & 0.04 & 1.27 & 0.05 & 1.27 & 0.04 & $1 \cdot 16$ & 0.05 \\
\hline \multicolumn{9}{|c|}{ LDL-C (mmol/l) } \\
\hline 0 week & 3.82 & 0.13 & 3.82 & 0.12 & 3.97 & 0.15 & 3.87 & 0.21 \\
\hline 8 week & 3.58 & 0.13 & $3 \cdot 71$ & 0.12 & 3.85 & 0.12 & 3.72 & 0.18 \\
\hline \multicolumn{9}{|l|}{ HDL-C:TC } \\
\hline 0 week & 0.26 & 0.01 & 0.24 & 0.01 & 0.23 & 0.01 & 0.24 & 0.01 \\
\hline 8 week & 0.26 & 0.01 & 0.24 & 0.01 & 0.23 & 0.01 & 0.23 & 0.01 \\
\hline \multicolumn{9}{|c|}{ HDL-C:LDL-C } \\
\hline 0 week & 0.36 & 0.01 & 0.35 & 0.02 & 0.33 & 0.01 & 0.34 & 0.02 \\
\hline 8 week & 0.39 & 0.02 & 0.35 & 0.02 & 0.34 & 0.01 & 0.34 & 0.02 \\
\hline \multicolumn{9}{|l|}{ ApoAl $(g / l)$} \\
\hline 0 week & 1.41 & 0.04 & 1.38 & 0.04 & 1.37 & 0.05 & 1.34 & 0.04 \\
\hline 8 week & 1.47 & 0.05 & 1.40 & 0.04 & 1.40 & 0.04 & 1.32 & 0.05 \\
\hline \multicolumn{9}{|l|}{ ApoB $(g / l)$} \\
\hline 0 week & 0.93 & 0.03 & 0.96 & 0.03 & 0.97 & 0.03 & 0.95 & 0.04 \\
\hline 8 week & $0.87^{\star}$ & 0.03 & $0.91^{*}$ & 0.03 & $0.92^{\star}$ & 0.03 & 0.93 & 0.04 \\
\hline \multicolumn{9}{|c|}{ ApoB/apoAl } \\
\hline 0 week & 0.67 & 0.02 & 0.70 & 0.03 & 0.72 & 0.03 & 0.74 & 0.04 \\
\hline 8 week & 0.62 & 0.03 & 0.67 & 0.03 & 0.67 & 0.03 & 0.74 & 0.04 \\
\hline \multicolumn{9}{|c|}{ ApoCll (mg/l) } \\
\hline 0 week & $65 \cdot 3$ & $4 \cdot 2$ & $63 \cdot 0$ & $4 \cdot 6$ & $64 \cdot 7$ & $5 \cdot 0$ & 61.5 & 3.8 \\
\hline 8 week & $53 \cdot 7^{*}$ & $3 \cdot 8$ & $52 \cdot 9^{\star}$ & $4 \cdot 3$ & $56 \cdot 8^{*}$ & 3.8 & $56 \cdot 5$ & $3 \cdot 1$ \\
\hline \multicolumn{9}{|c|}{ ApoCIII (mg/l) } \\
\hline 0 week & 118 & $5 \cdot 1$ & 117 & $6 \cdot 1$ & 119 & $5 \cdot 1$ & 113 & $5 \cdot 1$ \\
\hline 8 week & $107^{*}$ & $6 \cdot 2$ & $105^{\star \star}$ & 4.6 & $106^{*}$ & 4.9 & 110 & $5 \cdot 2$ \\
\hline \multicolumn{9}{|c|}{ ApoE (mg/l) } \\
\hline 0 week & 51.5 & $2 \cdot 8$ & $52 \cdot 1$ & 3.8 & $51 \cdot 7$ & $2 \cdot 9$ & $52 \cdot 6$ & $3 \cdot 3$ \\
\hline 8 week & $49 \cdot 8$ & $2 \cdot 6$ & $47 \cdot 8$ & $2 \cdot 7$ & $47 \cdot 4$ & 2.9 & $50 \cdot 7$ & 3.4 \\
\hline
\end{tabular}

TC, total cholesterol; HDL-C, HDL-cholesterol; LDL-C, LDL-cholesterol.

Mean values were significantly different within the group before and after the 8-week trial: ${ }^{\star} P<0.05$, ${ }^{\star \star} P<0.01$.

just increased to $1.0 \mathrm{~g} / \mathrm{d}$ from baseline, which is still higher than the FAO recommendation. The $n-6: n-3$ PUFA ratio in the pompano group was only decreased to $7 \cdot 3$, but this is also close to the recommendation of 6 . Accordingly, these improvements to the dietary fatty acids profile by inclusion of oily fish were also reflected in the fatty acid profile of plasma CPG, in which the percentage of EPA + DHA was significantly elevated in the three oily fish groups when compared to the control. Interestingly, when compared with the salmon and herring groups, the pompano group had about $80 \%$ less EPA intake and only $8 \%$ less DHA intake, but the net increased EPA, DHA, EPA + DHA and total $n-3$ PUFA in plasma CPG were comparable between the three oily fish groups. This could be explained by the different incorporation efficiency between EPA and DHA. Previous animal and cell studies have demonstrated that compared to DHA, exogenous EPA is much easier to be degraded by mitochondrial $\beta$-oxidation ${ }^{(24-26)}$. Thus, the differences in dietary EPA content would be moderated in the plasma fatty acid profile. Therefore, the present study provides more evidence that the incorporation of fish-sourced DHA is also more effective than EPA in humans.
Dietary inclusion of oily fish reduces serum TAG, but not cholesterol

To date, increasing evidence has suggested that there is a close link between CVD risk and hypertriacylglycerolaemia ${ }^{(27)}$ and, therefore, lowering circulating TAG levels could effectively help in reducing CVD prevalence. As compared to the numerous fish oil studies showing that marine $n$-3 PUFA lowers blood TAG, the effects of fish intake on blood TAG level are still not fully evaluated. Seierstad et $a l .{ }^{(28)}$ found that a salmon diet providing EPA + DHA at $2.9 \mathrm{~g} / \mathrm{d}$, but not $1.5 \mathrm{~g} / \mathrm{d}$, could significantly lower blood TAG levels in Norwegian subjects. In the present study, three oily fish diets provided $\mathrm{EPA}+\mathrm{DHA}$ intake at the level from 1.0 to $1.6 \mathrm{~g} / \mathrm{d}$, but they all significantly reduced serum TAG levels about $20 \%$ as compared to baseline. It has generally been known that the beneficial effects of $n-3$ LC-PUFA are more evident in dyslipidaemic subjects than in healthy subjects. Taking into account that hypertriacylglycerolaemia is more prevalent in the Chinese population than in the Western population ${ }^{(29,30)}$, and the baseline level of TAG in the present study is much 
Table 5. Serum concentrations of inflammation-related markers in the four groups at the beginning and end of the intervention period

(Mean values with their standard errors; medians and interquartile ranges)

\begin{tabular}{|c|c|c|c|c|c|c|c|c|}
\hline & \multicolumn{2}{|c|}{ Salmon } & \multicolumn{2}{|c|}{ Herring } & \multicolumn{2}{|c|}{ Pompano } & \multicolumn{2}{|c|}{ Control } \\
\hline & Mean & SEM & Mean & SEM & Mean & SEM & Mean & SEM \\
\hline \multicolumn{9}{|l|}{ HsCRP (mg/l) } \\
\hline 0 week & 2.00 & 0.24 & $2 \cdot 32$ & 0.27 & 2.01 & 0.20 & 1.98 & 0.25 \\
\hline 8 week & 1.98 & 0.19 & $2 \cdot 19$ & 0.20 & 2.03 & 0.27 & 2.06 & 0.23 \\
\hline \multicolumn{9}{|l|}{ IL-6 (ng/l) } \\
\hline 0 week & $268 \cdot 1$ & 9.37 & $255 \cdot 1$ & $10 \cdot 05$ & $242 \cdot 7$ & $10 \cdot 14$ & $241 \cdot 3$ & $9 \cdot 10$ \\
\hline 8 week & $245 \cdot 0^{*}$ & 5.75 & $237 \cdot 8$ & $10 \cdot 71$ & 224.9 & $7 \cdot 70$ & 237.8 & 7.96 \\
\hline \multicolumn{9}{|l|}{ ICAM-1 (ng/ml) } \\
\hline 0 week & $271 \cdot 0$ & 18.93 & $298 \cdot 1$ & $15 \cdot 11$ & $282 \cdot 8$ & $27 \cdot 01$ & $292 \cdot 2$ & $16 \cdot 80$ \\
\hline 8 week & $260 \cdot 7$ & $11 \cdot 70$ & $280 \cdot 1$ & 14.59 & $281 \cdot 1$ & $24 \cdot 11$ & 280.7 & 19.53 \\
\hline \multicolumn{9}{|l|}{ VCAM-1 (ng/ml) } \\
\hline \multicolumn{9}{|l|}{0 week } \\
\hline Median & \multicolumn{2}{|c|}{$319 \cdot 2$} & \multicolumn{2}{|c|}{$339 \cdot 8$} & \multicolumn{2}{|c|}{$308 \cdot 0$} & \multicolumn{2}{|c|}{$352 \cdot 2$} \\
\hline Interquartile range & \multicolumn{2}{|c|}{$281 \cdot 0-570 \cdot 2$} & \multicolumn{2}{|c|}{$283 \cdot 7-868 \cdot 6$} & \multicolumn{2}{|c|}{$286 \cdot 1-890 \cdot 5$} & \multicolumn{2}{|c|}{$291 \cdot 1-834 \cdot 8$} \\
\hline \multicolumn{9}{|l|}{8 week } \\
\hline Median & \multirow{2}{*}{\multicolumn{2}{|c|}{$\begin{array}{c}357 \cdot 8 \\
297 \cdot 7-536 \cdot 0\end{array}$}} & \multirow{2}{*}{\multicolumn{2}{|c|}{$\begin{array}{c}307 \cdot 3 \\
282 \cdot 5-687.7\end{array}$}} & \multicolumn{2}{|c|}{$326 \cdot 3$} & \multicolumn{2}{|c|}{$416 \cdot 1$} \\
\hline Interquartile range & & & & & 282.5 & $48 \cdot 4$ & 311.8 & $54 \cdot 1$ \\
\hline \multicolumn{9}{|l|}{ TNF- $\alpha(\mathrm{nmol} / \mathrm{ml})$} \\
\hline 0 week & $13 \cdot 3$ & 0.65 & $13 \cdot 7$ & 0.73 & $12 \cdot 9$ & 0.56 & $13 \cdot 0$ & 0.56 \\
\hline 8 week & $12 \cdot 0^{*}$ & 0.49 & $12 \cdot 2^{*}$ & 0.56 & 11.9 & 0.46 & $12 \cdot 8$ & 0.44 \\
\hline \multicolumn{9}{|l|}{ Adiponectin $(\mu \mathrm{g} / \mathrm{ml})$} \\
\hline 0 week & $6 \cdot 7$ & 0.45 & 6.9 & 0.46 & $7 \cdot 3$ & 0.35 & $7 \cdot 2$ & 0.53 \\
\hline 8 week & $7.4^{*}$ & 0.52 & $7 \cdot 8^{\star}$ & 0.63 & $7 \cdot 9$ & 0.49 & $7 \cdot 6$ & 0.52 \\
\hline
\end{tabular}

HsCRP, high-sensitivity C-reactive protein; ICAM-1, intercellular adhesion molecule-1; VCAM-1, vascular cell adhesion molecule-1.

${ }^{*}$ Mean values were significantly different within the group before and after the 8-week trial $(P<0.05)$.

higher than that in other similar studies performed in western countries, the effective dose of EPA + DHA needed to reduce TAG may be lower in hypertriacylglycerolaemic Chinese subjects than in Western subjects. Similarly, Lindqvist et $a l .{ }^{(16)}$ found that a herring diet providing EPA + DHA at only $1.2 \mathrm{~g} / \mathrm{d}$ significantly lowered blood TAG, but the decreased TAG showed no significant difference when compared to the reference diet in that study. Thus, the authors concluded that the total dietary composition (protein, carbohydrates and fat) had a larger impact on TAG. In the present study, the net TAG decrease in the salmon and herring groups was significantly larger than that of the control group; moreover, the tendency that the net decreased TAG was dose-dependent with the EPA + DHA intake in the three oily fish groups as salmon $\geq$ herring $>$ pompano was also noticed. This suggests that in the present study, dietary $\mathrm{EPA}+\mathrm{DHA}$ intake, rather than total dietary composition, plays a key role in decreasing serum TAG levels. In TAG metabolism, apoCII and apoCIII are important in TAG hydrolysis. ApoCII is a protein that activates lipoprotein lipase in capillaries, which hydrolyses TAG and thus provides NEFA for the cell. In contrast, apoCIII inhibits lipoprotein lipase and hepatic lipase, which is thought to inhibit hepatic uptake of TAG-rich particles. Although apoCII and apoCIII have opposite biochemical properties, elevated blood levels of both lipoproteins as signs of abnormal TAG-rich lipoprotein metabolism have been regarded as predictors for CVD incidence ${ }^{(31-33)}$. In the present study, accompanied by decreased serum TAG, significantly decreased serum apoCII and apoCIII were also observed in the oily fish

Table 6. Serum glucose and insulin levels and homeostasis model assessment of insulin resistance (HOMA-IR) of the four groups at the beginning and end of the intervention period

(Mean values with their standard errors)

\begin{tabular}{|c|c|c|c|c|c|c|c|c|}
\hline & \multicolumn{2}{|c|}{ Salmon } & \multicolumn{2}{|c|}{ Herring } & \multicolumn{2}{|c|}{ Pompano } & \multicolumn{2}{|c|}{ Control } \\
\hline & Mean & SEM & Mean & SEM & Mean & SEM & Mean & SEM \\
\hline \multicolumn{9}{|c|}{ Glucose (mmol/l) } \\
\hline 0 week & 5.53 & 0.14 & $5 \cdot 37$ & 0.10 & $5 \cdot 33$ & 0.11 & $5 \cdot 41$ & 0.17 \\
\hline 8 week & $5 \cdot 34$ & 0.13 & $5 \cdot 26$ & 0.07 & $5 \cdot 33$ & 0.10 & $5 \cdot 31$ & 0.13 \\
\hline \multicolumn{9}{|c|}{ Insulin $(\mu \mathrm{IU} / \mathrm{ml})$} \\
\hline 0 week & $15 \cdot 2$ & 1.09 & $16 \cdot 4$ & 1.60 & $15 \cdot 2$ & 1.02 & 14.9 & 1.36 \\
\hline 8 week & $15 \cdot 8$ & 0.90 & $16 \cdot 2$ & $1 \cdot 27$ & 14.9 & 1.08 & $15 \cdot 2$ & 1.39 \\
\hline \multicolumn{9}{|l|}{ HOMA-IR } \\
\hline 0 week & $3 \cdot 8$ & 0.35 & $4 \cdot 0$ & 0.40 & 3.6 & 0.27 & 3.7 & 0.36 \\
\hline 8 week & $3 \cdot 8$ & 0.29 & $3 \cdot 8$ & 0.31 & 3.5 & 0.26 & $3 \cdot 6$ & 0.38 \\
\hline
\end{tabular}


Table 7. Net changes* of parameters showing significant changes within groups after the 8-week oily fish intervention trial $\dagger$

(Mean values with their standard errors)

\begin{tabular}{|c|c|c|c|c|c|c|c|c|c|}
\hline & \multicolumn{2}{|c|}{ Salmon } & \multicolumn{2}{|c|}{ Herring } & \multicolumn{2}{|c|}{ Pompano } & \multicolumn{2}{|c|}{ Control } & \multirow[b]{2}{*}{ ANOVA $P$} \\
\hline & Mean & SEM & Mean & SEM & Mean & SEM & Mean & SEM & \\
\hline \multicolumn{10}{|c|}{ Fatty acids in CPG (\% total fatty acids) } \\
\hline EPA & $+1 \cdot 01^{\mathrm{b}}$ & 0.34 & $+1 \cdot 23^{b}$ & 0.35 & $+0.89^{a, b}$ & 0.20 & $+0 \cdot 16^{\mathrm{a}}$ & 0.18 & 0.041 \\
\hline $\mathrm{DHA}$ & $+1.45^{\mathrm{b}}$ & 0.23 & $+1.37^{b}$ & 0.27 & $+1 \cdot 10^{\mathrm{b}}$ & 0.16 & $+0 \cdot 16^{\mathrm{a}}$ & $0 \cdot 15$ & $<0.01$ \\
\hline $\mathrm{EPA}+\mathrm{DHA}$ & $+2 \cdot 46^{\mathrm{b}}$ & 0.41 & $+2 \cdot 60^{\mathrm{b}}$ & 0.46 & $+1.99^{b}$ & 0.21 & $+0.32^{\mathrm{a}}$ & 0.22 & $<0.01$ \\
\hline Total $n$-3 PUFA & $+2.53^{\mathrm{b}}$ & 0.40 & $+2 \cdot 72^{\mathrm{b}}$ & 0.47 & $+2.39^{\mathrm{b}}$ & 0.26 & $+0.33^{a}$ & 0.22 & $<0.01$ \\
\hline \multicolumn{10}{|c|}{ Serum lipids and lipoproteins } \\
\hline $\mathrm{TAG}(\mathrm{mmol} / \mathrm{l})$ & $-0.59^{b}$ & 0.09 & $-0.56^{\mathrm{b}}$ & 0.12 & $-0.49^{a, b}$ & 0.09 & $-0.21^{a}$ & 0.11 & 0.04 \\
\hline $\mathrm{ApoB}(\mathrm{mg} / \mathrm{l})$ & -0.06 & 0.03 & -0.04 & 0.02 & -0.04 & 0.03 & -0.02 & 0.03 & 0.762 \\
\hline ApoCll (mg/l) & -11.5 & 4.8 & $-10 \cdot 2$ & $4 \cdot 1$ & -7.9 & $3 \cdot 1$ & $-5 \cdot 0$ & 3.5 & 0.656 \\
\hline ApoCIII (mg/l) & $-10 \cdot 8$ & 4.9 & -12.5 & 3.8 & $-12 \cdot 3$ & 4.5 & -3.3 & $5 \cdot 8$ & 0.495 \\
\hline \multicolumn{10}{|l|}{ Inflammatory factors } \\
\hline IL-6 (ng/l) & $-23 \cdot 10$ & $10 \cdot 59$ & $-17 \cdot 30$ & $10 \cdot 12$ & $-17 \cdot 81$ & $9 \cdot 25$ & -3.53 & 7.95 & 0.505 \\
\hline TNF- $\alpha(n g / l)$ & $-1 \cdot 26$ & 0.62 & -1.47 & 0.58 & -1.01 & 0.51 & -0.17 & 0.53 & 0.384 \\
\hline Adiponectin $(\mu \mathrm{g} / \mathrm{ml})$ & +0.72 & 0.34 & +0.88 & 0.40 & +0.62 & 0.32 & +0.42 & 0.26 & 0.809 \\
\hline
\end{tabular}

CPG, choline phosphoglyceride.

${ }^{a, b}$ Mean values within a row with unlike letters were significantly different $(P<0.05)$

* + or - means net increase or decrease in values within a group after the 8-week oily fish trial.

†The post hoc comparison between groups was carried out using the least significant difference multiple comparison test (SPSS 13.0; SPSS, Inc.)

groups compared to baseline level, indicating that TAG metabolism was improved by the inclusion of oily fish.

A number of studies have shown that $n$-3 LC-PUFA had no significant effects on TC and LDL-C levels ${ }^{(10)}$. Similarly, in the present study, oily fish inclusion did not lead to significant alterations in the markers related to cholesterol metabolism, including TC, HDL-C and LDL-C, although apoB levels were lowered only in the oily fish groups as compared to baseline. However, our previous study showed that a salmon diet providing $\mathrm{EPA}+$ DHA at $2 \cdot 83 \mathrm{~g} / \mathrm{d}$ significantly increased serum HDL-C in dyslipidaemic adult Chinese men ${ }^{(14)}$. Probably because of the different EPA + DHA intake and sex difference of subjects between the two trials, we did not observe the favourable change of HDL-C in this study. However, the significantly decreased apoB observed in the oily fish groups still suggests that the inclusion of oily fish may contribute to the reduction of LDL, and thereby alleviate CVD risk.

\section{Beneficial effects of dietary inclusion of oily fish on serum inflammation-related markers}

Inflammation plays an important role in the initiation and the progression of atherosclerosis. Thus, it has been demonstrated to be at the centre of $\mathrm{CVD}^{(34,35)}$. Some epidemiological studies have indicated that inverse associations exist between $n$-3 LCPUFA or fish intake and some inflammatory markers, such as C-reactive protein, IL-6, intercellular adhesion molecule-1 and $\mathrm{TNF}-\alpha^{(36)}$. In our previous study of dyslipidaemic Chinese adult men, dietary inclusion of salmon could effectively lower serum IL-6 concentration as compared to the pork/chicken/beef group and the lean fish group. Similarly, in the present study, when compared with baseline levels, TNF- $\alpha$ and IL- 6 in the salmon group and TNF- $\alpha$ in the herring group were significantly reduced after the 8-week intervention. Accordingly, the serum level of adiponectin, which is an anti-inflammatory factor released from the adipose tissue that displays beneficial effects in the prevention of $\mathrm{CVD}^{(37)}$, increased significantly in the salmon and herring groups, but not in the pompano group. Considering that the salmon and herring diets provide $60 \%$ more EPA + DHA than the pompano diet $(1.6 v .1 .0 \mathrm{~g} / \mathrm{d})$, it can be deduced that relatively high EPA + DHA intake may be necessary for the beneficial regulation of inflammatory progress.

\section{Effects of dietary inclusion of oily fish on systemic insulin sensitivity}

In recent years, the incidence of type 2 diabetes mellitus has risen rapidly among middle-aged and elderly people in urban areas of China ${ }^{(38,39)}$. So the effect of any dietary modification on glucose metabolism and insulin sensitivity is of great concern. As an excellent source of EPA + DHA, oily fish intake was shown to have a protective effect on the development of insulin resistance through the reduction of insulin levels and increase in insulin sensitivity while maintaining pre-existing glucose concentrations ${ }^{(17,40)}$. However, excessive intake of $n$ - 3 LC-PUFA (greater than $10 \mathrm{~g} / \mathrm{d}$ ) may decrease insulin sensitivity and deteriorate glucose metabolism in subjects suffering from type 2 diabetes mellitus ${ }^{(41)}$. In the present study, we did not observe any changes in serum glucose, insulin concentrations and insulin sensitivity as reflected by the homeostasis model assessment of insulin resistance among the three oily fish groups, indicating that oily fish diets providing 1.0-1.6 g EPA + DHA/d do not affect glucose and insulin metabolism in dyslipidaemic middle-aged and elderly Chinese women.

\section{Comparison of salmon, herring and pompano as oily fish in reducing CVD risk markers}

As opposed to fish oil which serves only as a good source of $n$-3 LC-PUFA, oily fish is a more complete package of nutrients including not only $n$-3 LC-PUFA, but also taurine, arginine and glutamine which have also been shown to be beneficial for 
cardiovascular function $^{(42,43)}$. In addition, inclusion of oily fish in the diet can also improve dietary structure. For example, in the present study, both the salmon and herring groups had significantly lower SFA intake than the control, which could also have beneficial effects on CVD prevention. However, in the majority of scientific publications, the beneficial effects of oily fish in preventing CVD incidence are still mainly attributed to the $n$ - 3 LC-PUFA content, particularly the EPA + DHA content of oily fish. Therefore, the content of EPA + DHA in oily fish is believed to be the most important index to evaluate for determining the potential benefits in the prevention of CVD. In the present study, dietary inclusion of salmon and herring provided almost equal EPA + DHA intakes of $1.6 \mathrm{~g} / \mathrm{d}$, which was much higher than $1.0 \mathrm{~g} / \mathrm{d}$ in the pompano group, and $0.05 \mathrm{~g} / \mathrm{d}$ in the control group. Interestingly, either a salmon, herring or pompano diet could significantly increase plasma $n$-3 LC-PUFA concentrations and reduce serum TAG during the 8-week intervention period, indicating that even the pompano diet which provides a relatively low amount of EPA + DHA can still effectively moderate CVD risk. However, when net TAG decrease was used to perform multiple comparisons between groups, only the salmon and herring groups, but not the pompano group, showed significantly larger TAG decrease than the control group. This could be caused by the relatively small sample size in the present study (only thirty participants per group), which might amplify the interference of inter-individual variability on the final results and lead to the potential significant difference between the pompano and control groups being eliminated. Alternatively, this also suggests that higher EPA + DHA intake had stronger effects in reducing CVD risk markers. Furthermore, data concerning inflammation-related markers more clearly indicated the different contributions of three oily fish to prevent potential inflammation: as compared to baseline levels, the salmon diet with the highest EPA + DHA intake affected three inflammation-related markers (IL- 6 , TNF- $\alpha$ and adiponectin), followed by the herring diet with the second highest $\mathrm{EPA}+$ DHA intake affecting two markers (TNF- $\alpha$ and adiponectin), whereas the pompano diet with the lowest $\mathrm{EPA}+$ DHA intake did not affect any inflammation-related markers. Taking blood lipids and inflammation-related markers into consideration, salmon, herring and pompano could provide benefits in preventing CVD risk with different efficacy as salmon $\geq$ herring $>$ pompano.

\section{Conclusion}

The present study demonstrates that it is feasible to include salmon, herring and pompano as oily fish within the Chinese diet for middle-aged and elderly women. During the 8-week intervention period, consumption of the three oily fish can effectively raise serum CPG $n$-3 LC-PUFA levels, but only the salmon and herring diets significantly reduced plasma TAG as compared to the control group. However, when compared with baseline levels, the three oily fish diets significantly decreased serum concentrations of TAG, apoB, apoCII and CIII, but only the salmon and herring diets significantly lowered $\mathrm{TNF}-\alpha$ while raising adiponectin levels, In addition, the salmon diet also reduced the serum concentration of IL-6. A dose-dependent relationship was found to exist between the beneficial effects of the oily fish diet and their EPA + DHA intake as salmon $\geq$ herring $>$ pompano. Taken together, we conclude that oily fish may play a beneficial role in alleviating CVD risk dosedependently by their EPA + DHA content.

\section{Acknowledgements}

The present study was financed by the Norwegian Research Council (project no. 165303) and the Norwegian Royal Ministry of Fisheries and Coastal Affairs. The Norwegian Seafood Export Council provided salmon fillets. The authors specially thank Lise Madsen for her invaluable help in manuscript organisation. The authors' contributions to this study were as follows: J. Z. designed and performed the study, analysed the data and wrote the manuscript; C. W., L. L., Q. M., L. M. and P. S. took responsibility for the blood sample collection, laboratory measurements and health survey investigation; L. F. gave advice on the data analysis and contributed to the manuscript writing; Z.-Y. D. designed the study, analysed the data and wrote the manuscript. The authors thank all participants for their cooperation in this intervention trial. The authors declare no conflicts of interest.

\section{References}

1. World Health Organization (2005) Preventing Chronic Diseases: A Vital Investment. http://www.who.int/chp/ chronic_disease_report/part1/zh/index1.html

2. Nettleton JA, Polak JF, Tracy R, et al. (2009) Dietary patterns and incident cardiovascular disease in the Multi-Ethnic Study of Atherosclerosis. Am J Clin Nutr 90, 647-654.

3. Heidemann C, Schulze MB, Franco OH, et al. (2008) Dietary patterns and risk of mortality from cardiovascular disease, cancer, and all causes in a prospective cohort of women. Circulation 118, 230-237.

4. He YN, Zhai FY, Wang ZH, et al. (2005) Intake, food source and changes of dietary energy, protein, fat among Chinese people. Acta Nutr Sin 27, 358-366.

5. Zhang J, Meng LP, Jiang YR, et al. (2009) Dietary fatty acids intake and the food source among Chinese adults. Acta Nutr $\sin$ 31, 424-427.

6. Ministry of Health, People's Republic of China (2010) Chinese Health Statistical Digest. http://www.moh.gov.cn/ publicfiles/business/htmlfiles/zwgkzt/ptjty/digest2010/index. html

7. Mozaffarian D \& Rimm EB (2006) Fish intake, contaminants, and human health. Evaluating the risks and the benefits. JAMA 296, 1885-1899.

8. Saravana P, Davidson NC, Schmidt EB, et al. (2010) Cardiovascular effects of marine omega-3 fatty acids. Lancet $\mathbf{3 7 5}$, $540-550$.

9. De Caterina R (2011) n-3 Fatty acids in cardiovascular disease. $N$ Engl J Med 364, 2439-2450.

10. Harris WS (1997) n-3 Fatty acids and serum lipoproteins: human studies. Am J Clin Nutr 65, 1645S-1654S

11. Moore CS, Bryant SP, Mishra GD, et al. (2006) Oily fish reduces plasma triacylglycerols: a primary prevention study in overweight men and women. Nutrition 22, 1012-1024. 
12. Psota TL, Gebauer SK \& Kris-Etherton P (2006) Dietary omega-3 fatty acid intake and cardiovascular risk. $\mathrm{Am} \mathrm{J}$ Cardiol 98, 3i-18i.

13. He K, Liu K, Daviglus ML, et al. (2009) Associations of dietary long-chain $n-3$ polyunsaturated fatty acids and fish with biomarkers of inflammation and endothelial activation (from the Multi-Ethnic Study of Atherosclerosis [MESA]). Am J Cardiol 103, 1238-1243.

14. Zhang J, Wang CR, Li LX, et al. (2010) Inclusion of Atlantic salmon in the Chinese diet reduces cardiovascular disease risk markers in dyslipidemic adult men. Nutr Res 30, 447-454.

15. Hallund J, Madsen OM, Bügel SH, et al. (2010) The effect of farmed trout on cardiovascular risk markers in healthy men. Br J Nutr 104, 1528-1536.

16. Lindqvist HM, Langkilde AM, Undeland I, et al. (2009) Herring (Clupea harengus) intake influences lipoproteins but not inflammatory and oxidation markers in overweight men. Br J Nutr 101, 383-390

17. Navas-Carretero S, Pérez-Granados AM, Schoppen S, et al. (2009) An oily fish diet increases insulin sensitivity compared to a red meat diet in young iron-deficient women. Br J Nutr 102, 546-553.

18. Maas AH \& Franke HR (2009) Women's health in menopause with a focus on hypertension. Neth Heart J 17, 68-72.

19. Folch J, Lees M \& Sloane Stanley GH (1957) A simple method for the isolation and purification of total lipides from animal tissues. J Biol Chem 226, 497-509.

20. Food and Agriculture Organization (2010) Fats and Fatty Acids in Human Nutrition - Report of an Expert Consultation. Food and Nutrition Paper 91, ISSN 0254-4725, pp. 79.

21. Kris-Etherton PM, Taylor DS, Yu-Poth SM, et al. (2000) Polyunsaturated fatty acids in the food chain in the United States. Am J Clin Nutr 21, 179S-188S.

22. Givens DI \& Gibbs RA (2008) Current intakes of EPA and DHA in European populations and the potential of animalderived foods to increase them. Proc Nutr Soc 67, 273-280.

23. Chinese Nutrition Society (2000) Chinese Dietary Reference Intakes. Beijing: China Light Industry Press. ISBN 7-50192895-9. pp. 102.

24. Osmundsen H, Braud H, Beauseigneur F, et al. (1998) Effects of dietary treatment of rats with eicosapentaenoic acid or docosahexaenoic acid on hepatic lipid metabolism. Biochem J 331, 153-160.

25. Du ZY, Araujo P, Stubhaug I, et al. (2010) Unbound DHA causes a high blank value in $\beta$-oxidation assay: a concern for in vitro studies. Eur J Lipid Sci Technol 112, 333-342.

26. Du ZY, Ma T, Winterthun S, et al. (2010) $\beta$-Oxidation modulates metabolic competition between eicosapentaenoic acid and arachidonic acid regulating prostaglandin E2 synthesis in rat hepatocytes-Kupffer cells. Biochim Biophys Acta 1801, 526-536.

27. Miller M, Stone NJ, Ballantyne C, et al. (2011) Triglycerides and cardiovascular disease: a scientific statement from the American Heart Association. Circulation 123, 2292-2333.
28. Seierstad SL, Seljeflot I, Johansen O, et al. (2005) Dietary intake of differently fed salmon; the influence on markers of human atherosclerosis. Eur J Clin Invest 35, $52-59$.

29. Ford ES, Mokdad AH, Giles WH, et al. (2003) Serum total cholesterol concentrations and awareness, treatment, and control of hypercholesterolemia among US adults: findings from the National Health and Nutrition Examination Survey, 1999 to 2000. Circulation 107, 2185-2189.

30. Zhao WH, Zhang J, Zhai Y, et al. (2007) Blood lipid profile and prevalence of dyslipidemia in Chinese adults. Biomed Environ Sci 20, 329-335.

31. Scheffer PG, Teerlink T, Dekker JM, et al. (2008) Increased plasma apolipoprotein C-III concentration independently predicts cardiovascular mortality: the Hoorn Study. Clin Chem 54, 1325-1330.

32. Gerber Y, Goldbourt U, Cohen H, et al. (2002) Association between serum apolipoprotein C(II) concentration and coronary heart disease. Prev Med 35, 42-47.

33. Furtado JD, Campos H, Sumner AE, et al. (2010) Dietary interventions that lower lipoproteins containing apolipoprotein C-III are more effective in whites than in blacks: results of the OmniHeart trial. Am J Clin Nutr 92, 714-722.

34. Pearson TA, Mensah GA, Alexander RW, et al. (2003) Markers of inflammation and cardiovascular disease: application to clinical and public health practice: a statement for healthcare professionals from the Centers for Disease Control and Prevention and the American Heart Association. Circulation 107, 499-511.

35. Libby P (2006) Inflammation and cardiovascular disease mechanisms. Am J Clin Nutr 83, 456S-460S.

36. Lopez-Garcia E, Schulze MB, Manson JE, et al. (2004) Consumption of $(n-3)$ fatty acids is related to plasma biomarkers of inflammation and endothelial activation in women. J Nutr 134, 1806-1811.

37. Matsuzawa Y, Funahashi T, Kihara S, et al. (2004) Adiponectin and metabolic syndrome. Arterioscler Thromb Vasc Biol 24, 29-33.

38. Zhang J, Wang CR, Fu P, et al. (2007) Study on type 2 diabetes mellitus in urban China. Chin J Prev Med 41, 4-7.

39. Ning G, Hong J, Bi Y, et al. (2009) Progress in diabetes research in China. J Diabetes 1, 163-172.

40. Feskens EJ, Bowles CH \& Kromhout D (1991) Inverse association between fish intake and risk of glucose intolerance in normoglycemic elderly men and women. Diabetes Care $\mathbf{1 4}$, 935-941

41. Borkman M, Chisholm DJ, Furler SM, et al. (1989) Effects of fish oil supplementation on glucose and lipid metabolism in NIDDM. Diabetes 38, 1314-1319.

42. Militante JD \& Lombardini JB (2002) Treatment of hypertension with oral taurine: experimental and clinical studies Amino Acids 23, 381-393.

43. Moncada S \& Higgs A (1993) L-Arginine-nitric oxide pathway. N Engl J Med 329, 2002-2012. 